\title{
LANTING
}

\section{MUSEUM KOMIK DI BANJARBARU}

\author{
Muhammad Rifky Faisal Subhan \\ Program Studi Teknik Arsitektur Fakultas Teknik Universitas Lambung Mangkurat \\ 1610812210015@mhs.ulm.ac.id
}

\author{
Mohammad Ibnu Sa'ud \\ Program Studi Teknik Arsitektur Fakultas Teknik Universitas Lambung Mangkurat \\ ibnusaud@ulm.ac.id
}

\begin{abstract}
ABSTRAK
Komik Indonesia memiliki sejarah panjang dan berkembang dalam kategori yang sangat beragam dan dulu pernah berperan penting sebagai media komunikasi visual di Indonesia. Permasalahan yang dihadapi mengenalkan kembali keragaman sejarah perjalanan komik di Indonesia dari awal hingga sekarang melalui rancangan museum dalam ruang-ruang penceritaan yang kronologis. Metode untuk menyelesaikan permasalahan yaitu dengan menggunakan metode analogi simbolik, dengan menganalogikan bagian utama dari komik, yaitu panel cerita sebagai ruang, parit di antara panel sebagai sirkulasi antar ruang, dan hubungan antar panel sebagai urutan cerita. Konsep sekuen antar panel dengan jeda berupa parit menjadi pilihan dalam menghasilkan desain, yaitu menghubungkan antar ruang dan ruang yang saling berbeda dengan sirkulasi secara linier dan kronologis.
\end{abstract}

Kata kunci: Museum, Komik, Analogi.

\section{ABSTRACT}

Indonesian comics have a long and growing history in very diverse categories and had played an important role in the past as a medium for visual communication in Indonesia. The problems faced are reintroducing the diversity of the history of comics in Indonesia from the beginning to the present through the design of the museum in chronological storytelling spaces. The method for solving the problem is by using the symbolic analogy method, by analogizing the main part of the comic, namely the story panels as spaces, the trenches between panels as circulation between spaces, and the relationship between panels as story sequences. The concept of sequences between panels with breaks in the form of trenches is an option in producing designs, namely connecting spaces and spaces that are different from each other with a linear and chronological circulation.

Keyword: Museum, Comic, Analogy.

\section{PENDAHULUAN}

Komik adalah sebuah media yang menggunakan gambar dalam mengekspresikan sebuah ide, biasanya gambar bergabung dengan teks atau penjelasan visual lain. Penggunaan perangkat tertulis seperti balon percakapan dan penjelasan yang menunjukkan sebuah perbincangan, cerita, efek suara, dan keterangan yang terkait. 


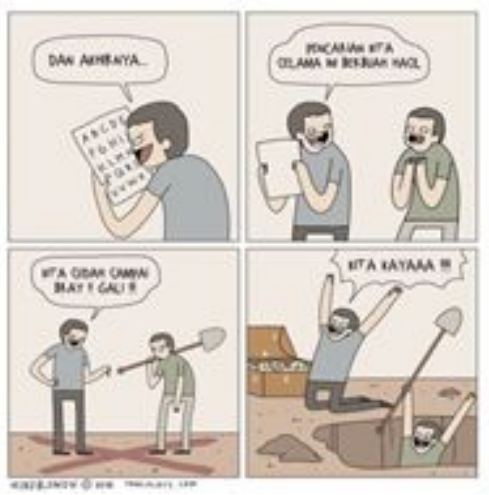

Gambar 1, komik sebagai media gambar dengan kombinasi teks.

Sumber:https://www.idntimes.com/life/inspira tion/febrina-melinda/10-comicstrip-tahilalatsyang-membuat-kamu-berpikir-keras-c1c2

Di Indonesia, dulunya komik sudah tampak pada saat zaman prasejarah, yaitu dari relief candi-candi seperti Prambanan dan Borobudur. Walaupun bentuknya tidak serupa seperti komik sekarang, tapi dinding candi sebenarnya sudah bercerita lewat gambar, bahkan adegannya sudah tersusun pada panel yang berurutan. Begitu juga dengan goa leang-leang di Sulawesi dengan gambar-gambar seperti hewan-hewan liar besar dan telapak tangan dengan susunan gambar yang kompleks. Hingga wayang beber yang bernarasi dengan gambar beralaskan kain.

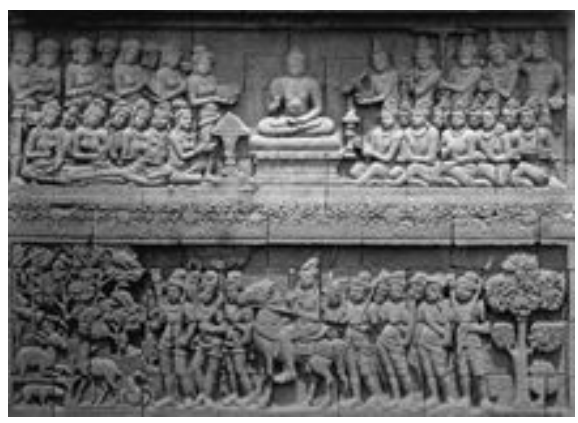

Gambar 2, relief batu candi Borobudur. Sumber:https://www.1001malam.com/travel/ candi-borobudur-kemegahan-arsitektur-abad -ke-9-yang-masih-mengundang-misteril

Pada tahun 1930, komik Indonesia pertama kali muncul dalam bentuk strip dengan nama Put On karya Kho Wang Gie di harian Sin Po (surat kabar Tionghoa dengan bahasa Melayu). Bercerita seorang tokoh gendut peranakan Cina yang selalu sial dan menjadikan hal tersebut sebagai humor dalam kisah sehari-hari. Diciptakan oleh Kho Wang Gie pada saat masyarakat keturunan Tionghoa di Indonesia yang merasa gelisah untuk mencari identitas sebenarnya, dan tampil sebagai warga yang menganggap Indonesia adalah tanah airnya yang sejati. Dan pada akhirnya komik Put On menjadi tonggak komik modern Indonesia.

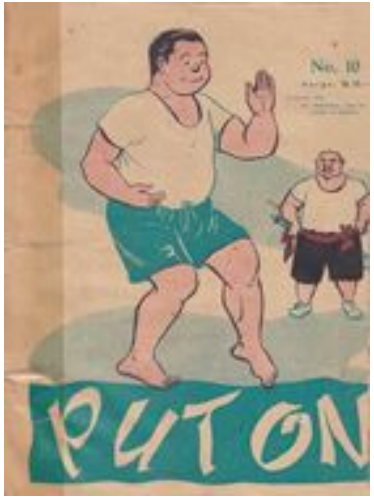

Gambar 3, Put On komik pertama di Indonesia.

Sumber:https://www.goodnewsfromindonesi a.id/2020/08/31/perkembangan-komik-di-ind

onesia-dari-era-cetak-sampai-digital

Dari perkembangan komik tersebut, masih banyak orang Indonesia yang tidak mengenal atau mengetahui tentang itu, karena orang Indonesia sangat minim untuk membuka kembali cerita penopang komik-komik yang hadir di masa sekarang. Padahal jika diikuti dari awal, komik Indonesia memiliki banyak sekali kategori dan bahkan mengalahkan komik luar negeri karena saking banyaknya.

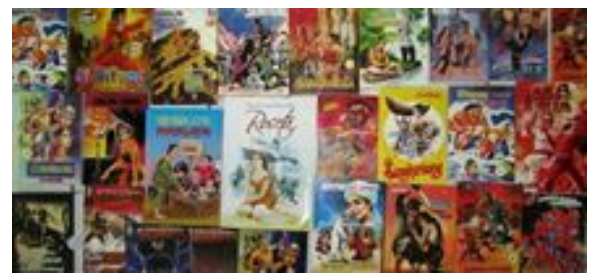

Gambar 4, berbagai macam genre. Sumber:https://www.alan.com/komik-komiku s-indonesia/ 
Untuk mengenalkan komik Indonesia, salah satu caranya adalah dengan mengenalkan kembali bahwa Indonesia dulunya juga menghasilkan banyak sekali komik dengan berbagai macam genre, walaupun mengalami masa-masa kejayaan hingga kemunduran. Dalam mengenalkan kembali perkembangan komik, dibutuhkan wadah yang bisa menampung berbagai macam tentang komik di Indonesia. Wadah yang dapat mewujudkannya berupa museum. Museum adalah wadah yang cocok sebagai tempat untuk mengenalkan dan menceritakan kembali perkembangan komik di Indonesia.

\section{PERMASALAHAN}

Berdasarkan latar belakang yang ada, permasalahan arsitektural Museum Komik di Banjarbaru adalah "Bagaimana rancangan Museum Komik yang dapat mengenalkan kembali sejarah atau perjalanan komik di Indonesia dari awal hingga sekarang dalam ruang-ruang".

\section{TINJAUAN PUSTAKA}

\section{A. Komik Indonesia}

Menurut Marcel Boneff (dalam buku Komik Indonesia, 1976), sejarah komik indonesia bisa dijelajahi hingga era prasejarah. Bukti perdana adalah yang ditemukan pada tugu-tugu keagamaan. Kemudian, ke era setelahnya, ada pewayangan yang menunjukkan cara bercerita menggunakan gambar yang dapat disebut sebagai asal mula komik. Bisa dilihat bahwa ketika para seniman Indonesia mampu membuat komik, dan ingin memproduksi komik asli yang bisa menghadapi produksi komik Amerika yang mendominasi, dengan kembali ke wayang untuk bukan sekedar tema, tapi untuk menghasilkan dramatisasi dan konvensi pencitraan.

Sekarang, komik Indonesia lebih banyak dijumpai seperti karya komikus dari Jepang, karena sangat banyak terdapat di rak toko buku di sekitar. Suksesnya komik ini aktif para era 1990 - 2000 an di Indonesia.

Padahal sebelum pasar Indonesia diinvasi oleh komik Jepang, komik nasional juga pernah berperan menjadi sahibulbait. Sebagai contoh, Si Buta dari Gua Hantu karya Ganes Th, Gundala karya Hasmi, Jaka Sembung karya Djair Warni hingga Panji Tengkorak karya Hans Jaladara yang pernah berkuasa pada 1960-an.

Komik di Indonesia memiliki 4 era yang berkesinambungan, yaitu era :

1. Era Awal (1930 - 1950 an)

Marcel Boneff, asal Perancis pernah melakukan penelitian terhadap komik Indonesia hingga muncul pertama kali di koran-koran pada tahun 1930 an dalam bentuk komik strip. Lalu pada tahun 1950 an, komik barat mulai menginvasi dan membuat komikus Indonesia mengikuti gaya gambar komik barat dan membuat komik Indonesia mengalami perubahan dalam penerbitan dengan bentuk buku. Sejak saat itu, komik Indonesia dikenal secara perlahan.

2. Era Kejayaan (1960 - 1970 an)

Komik Indonesia mengalami kebangkitan atau kejayaan pada tahun 1960 an. Banyaknya karakter ikonik yang membuat masyarakat tertarik dan menyukai komik Indonesia pada saat itu. 
3. Era Kemunduran (1980 - 1990 an)

Era kemunduran ditandai dengan adanya komik Eropa dan Jepang yang menguasai pasar Indonesia, karena pada saat itu penerbit lebih memilih menerbitkan komik luar daripada komik dalam negeri. Tapi ada sedikit komik Indonesia pada saat itu yang masih bisa bertahan.

\section{Era Sekarang (2000 - sekarang)}

Era ini terbagi menjadi dua, yaitu indie dan penerbitan oleh penerbit. Disebut indie karena banyaknya penerbit yang tidak mendukung para komikus untuk berkarya, dan melakukan produksi secara independen dan menyebarkannya dalam komunitas terbatas. Lalu secara perlahan penerbit di Indonesia menyadari komik Indonesia layak untuk diterbitkan. Pada masa ini, komik Indonesia mengalami perubahan dari bentuk cetak menuju digital.

\section{B. Tinjauan Arsitektur}

Dalam Peraturan Pemerintah RI No. 19 Tahun 1995, museum diartikan sebagai lembaga, wadah penyimpanan, pemeliharaan, perlindungan, dan pemanfaatan benda-benda fisik hasil dari budaya manusia bersama lingkungannya untuk membantu dalam perlindungan dan pelestarian aset bangsa. Dan dalam Ayo Kita Mengenal Museum, 2009, museum adalah badan yang ditujukan untuk orang banyak secara umum. Museum berfungsi mengoleksi, memelihara, dan mempertunjukkan serta mengabadikan aset budaya dari masyarakat dengan tujuan pembelajaran, eksplorasi, dan kesukaan atau rekreasi.

Sedangkan menurut International Council of Museums (ICOM), museum merupakan badan nirlaba tetap dengan tujuan pelayanan terhadap masyarakat, bersifat umum, yang memperoleh, mengabadikan, mengkaji, mengomunikasikan, dan mempertunjukkan aset kemanusiaan dan lingkungan yang memiliki fisik atau non fisik sebagai edukasi dan bersenang-senang.

Adapun pengertian museum menurut para ahli :

\section{Advanced Dictionary}

"Museum sebagai bangunan yang di dalamnya mempertunjukkan berbagai benda dan menjadi representasi dari sejarah, seni, ilmu pengetahuan, dan sebagainya."

\section{Sri Soejatmi}

"Museum sebagai lembaga dengan tujuan mengabadikan dan mewariskan budaya dengan mengumpulkan, menyimpan, merawat, memamerkan, dan juga mengkomunikasikannya kepada masyarakat."

3. Douglass A. Allan

"Museum adalah bangunan dengan bentuk yang sederhana untuk mengoleksi benda-benda untuk diinspeksi, dipelajari, dan dinikmati."

\section{PEMBAHASAN}

\section{A. Lokasi}

Site dipilih di bagian Banjarbaru Utara karena merupakan kawasan pendidikan dan perdagangan atau jasa, karena museum memiliki tujuan preservasi dan konservasi, edukasi, dan rekreasi. Luas lahan mencapai 9988,23 $\mathrm{m}^{2}$. 


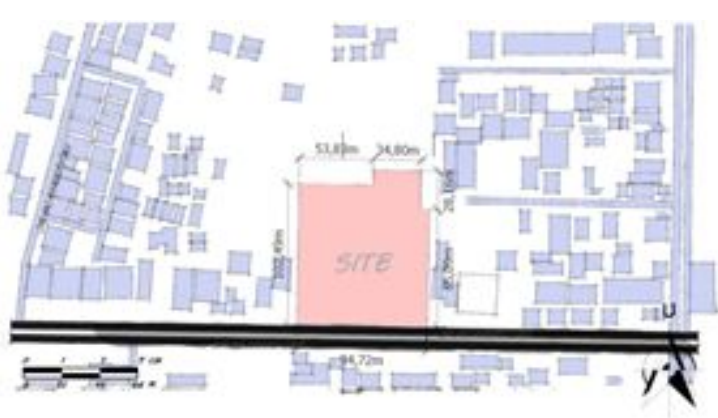

Gambar 5, eksisting tapak

Sumber: Analisis Pribadi (2020)
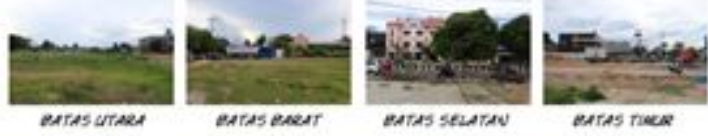

Gambar 6, batas tapak

Sumber: Analisis Pribadi (2020)

\section{B. Konsep Rancangan}

Museum komik bertujuan untuk mengenalkan kembali perkembangan komik di Indonesia dari awal hingga sekarang, dengan memberikan berbagai macam informasi terhadap konflik yang terjadi saat perkembangan dan komik-komik yang ada pada saat itu. Untuk membawa pengunjung agar dapat memahami perkembangan komik dari awal hingga sekarang, dibutuhkan alur cerita yang dapat membuat pengunjung mengetahui dan mengikuti bagaimana perkembangan komik berlangsung.

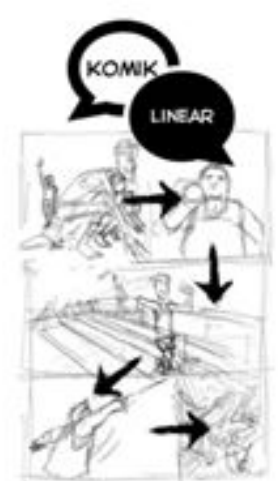

Gambar 7, konsep program Sumber: Analisis Pribadi (2020)

Dari permasalahan arsitektur yang menyatakan untuk mengenalkan kembali komik di Indonesia adalah dengan menggunakan konsep yang membantu menyelesaikan dan mencapai tujuan, yaitu konsep dari sebuah komik. Konsep komik berupa gambar-gambar di dalam panel yang tersusun secara berurutan atau linier dan dibatasi oleh parit. Karena panel tersusun secara berurutan, artinya panel harus memiliki hubungan antara satu panel dengan panel yang lainnya. Panel dan parit merupakan salah satu dari simbol dari komik, maka dari itu bentuk analogi dari panel adalah ruang dan parit adalah sirkulasi.

\section{HASIL}

Bentuk ruang yang telah tersusun dengan analogi simbolik dari sebuah komik, menghasilkan susunan yang menyesuaikan dari panel sebagai ruang dan parit sebagai sirkulasi. 

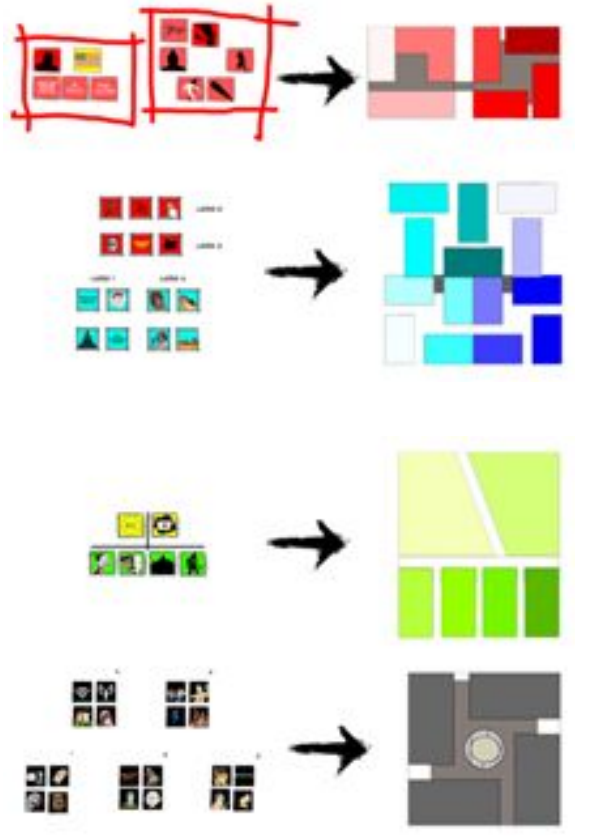

Gambar 8, susunan ruang Sumber: Analisis Pribadi (2020)

Susunan era dihubungkan dengan membentuk seperti susunan panel yang mana era awal berada di lantai 2, era kebangkitan di lantai 2 dan 3, menuruni lantai 1 ke era kemunduran, dan terakhir menuruni basement untuk menuju ke era sekarang.
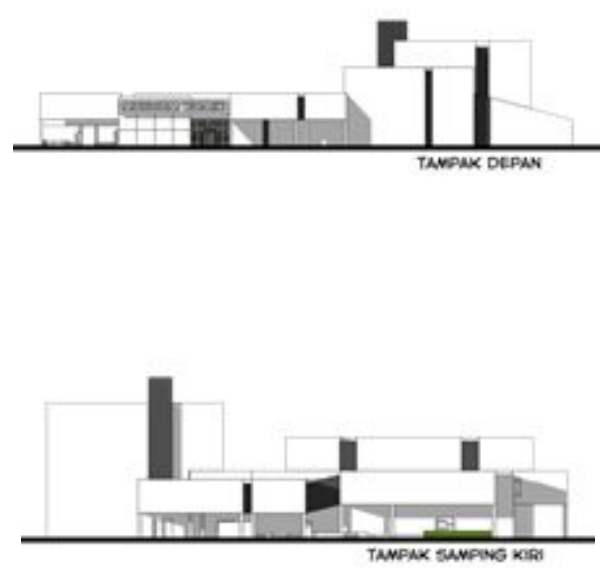
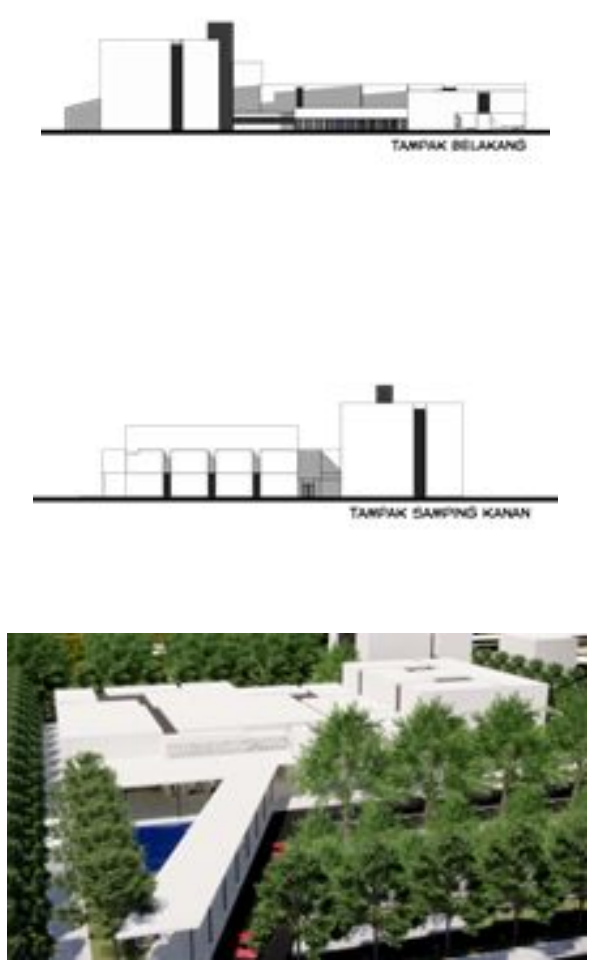

Gambar 9, hasil rancangan.

Sumber: Analisis Pribadi (2020)

\section{KESIMPULAN}

Rancangan museum komik yang dapat mengenalkan kembali perkembangan komik di Indonesia adalah dengan menggunakan analogi simbolik dari bagaimana cara membaca komik, yaitu dengan membaca secara berurutan. Artinya ruang-ruang disusun secara berurutan agar bisa dilihat dan dipahami oleh pengunjung bagaimana perkembangan komik di Indonesia berlangsung di dalam ruang-ruang.

Konsep yang digunakan adalah konsep komik, yaitu sebuah konsep dimana ruang-ruang museum dianalogikan sebagai panel dan sirkulasi sebagai parit jika di dalam komik. Walaupun isi panel berbeda-beda, tetapi semua harus 
berhubungan. Begitu juga dengan ruang-ruang dalam museum, harus saling berhubungan walaupun memiliki perbedaan dalam tiap ruangnya.

\section{DAFTAR PUSTAKA}

\section{Referensi Buku dan Jurnal}

Asiarto, L. (2008). Pedoman Museum Indonesia.

Boneff, Marcel. Komik Indonesia. Kepustakaan Populer Gramedia, 1998.

Ching, Francis D.K. 2008. Arsitektur: Bentuk, Ruang, dan Tatanan Edisi Ketiga. Hanggan Situmorang, Penerjemah. Jakarta (ID): Penerbit Erlangga. Terjemahan dari: Architecture: Form, Space, \& Order.

Direktorat Museum (2009). Ayo Kita Mengenal Museum.

McCloud, Scott. Memahami komik. Kepustakaan Populer Gramedia, 2001.

Neufert, E. (1996). Data Arsitek JI. 3. Erlangga. 